\title{
Stress and burnout in teaching. Study in an inclusive school workplace
}

\section{BACKGROUND}

Teaching is a profession associated with high levels of stress and burnout, affecting teachers' performance in the workplace. The main goal of the current study is to investigate stress and burnout conditions of teachers working presently in inclusive schools and the corresponding influence of personal variables.

\section{PARTICIPANTS AND PROCEDURE}

Participants were 7086 regular teachers, or non-specialists, and 442 special education teachers, or specialists $(N=7528)$.

\section{RESULTS}

Non-specialist teachers showed higher levels of burnout than specialist teachers in inclusive schools. Additionally, the results showed that higher levels of burnout are correlated with vulnerability to stress (perfectionism, inhibition, lack of social support, adverse living conditions, dramatization of existence and subjugation), in both groups of teachers. Non-specialists with more professional experience showed a high global score on burnout. In both groups, teachers with a higher level of training (academic degree and specialization) showed lesser vulnerability to stress, especially lower dependence. Concerning the predictors of burnout, vulnerability to stress played an important role as a predictor in both groups, suggesting that more vulnerable teachers are more prone to develop burnout, fatigue and exhaustion.

\section{CONCLUSIONS}

Stress emerges as an important predictor of burnout. Nonspecialist teachers are more exposed to burnout and stress in an inclusive workplace, because they have to deal with new demands, requiring new resources, especially new professional skills. On the other hand, teachers with more academic and professional training show higher resilience to stress and more independence, suggesting the crucial value of training to improve an inclusive school workplace. Training can have an important impact on stress/burnout and consequently on the professional performance and efficacy of teachers in inclusive schools.

\section{KEY WORDS}

stress in teachers; burnout; inclusive school as workplace; inclusion 


\section{BACKGROUND}

According to the 2006 Convention of the United Nations on the rights of persons with disabilities, signatory countries are obliged accept children with disabilities in regular schools, in order to promote their social and educational inclusion (The United Nations, 2006). However, this is not always true, especially for youngsters with severe and multiple difficulties having difficulties in daily activities of self-care, learning,

Adelinda A.

Candeias,

Edgar Galindo, Inês Calisto, Liberata Borralho, Konrad Reschke communication, mobility, as well as in participating in education or other activities. Barriers to inclusion of children with disabilities can be theoretical (stereotypes, prejudices, values, etc.), or practical and organizational (practitioners use different approaches to evaluate and intervene with children) (Simeonsson et al., 2010). In 2006, the Portuguese Government adopted the First Action Plan for the Inclusion of Persons with Disabilities or Disability for the years 20062009. Since 2008, inclusive education for all children in regular schools has been compulsory (Decreto-Lei $n^{\circ} 3 / 2008$ ). To support this process, a biopsychosocial model of assessment and intervention and the International Classification of Functioning, Disability and Health (ICF) (World Health Organization, 2001) were progressively adopted by regular schools to describe and assess the functional status and capabilities of persons with disabilities. In a short period of time, the educational community (teachers of special education, regular education teachers, administrators and other practitioners) have been obliged to use the ICF extensively. Since then, various training and information campaigns have been carried out across the country, aiming to enlighten and empower the educational community in order to include and teach all students in regular schools. The Ministry of Education supported by universities and polytechnic institutes organized a Special Education Training Course devoted to special education teachers and regular teachers (Candeias et al., 2013). The above-mentioned ICF (and the version for children and youth, ICF-CY) assesses the child or young person according to different points of view: components of functioning and disability and contextual factors, as well as the interactions established between them. It is essential to consider the contributions of several stakeholders, such as the classroom teacher/director of the class, special education teacher, social worker, psychologist, health service officers, operational assistants, and others. It is the work of a multidisciplinary team. This team is responsible for the whole process, including the assessment of the child, the definition of the responsibilities and the educational measures to be applied and the development of an Individual Educational Programme (IEP) to be approved by the Pedagogical Council and ratified by the Director of the School.

The introduced changes require new educational practices, creating a source of stress for teachers working with children and youth with disabilities (Gersten et al., 2001), as a consequence of greater responsibilities associated with a population usually more difficult to motivate, to teach and to evaluate (Carlotto, 2011; Etzion, 2020; Pinto \& Alvarez, 2016). Some studies indicate that the more teachers perceive the stressful situation in question as a threat or loss, the more it generates emotional exhaustion, the more teachers' well-being decreases, and the more the difficulties with the management of such students (and thus their learning abilities and well-being in school) increase, creating conditions for students' alienation, disorientation, school failure and drop-out (Boujut et al., 2016; Evers \& Tomic, 2003; Whitaker et al., 2015). New professional functions imply reckonings that can be perceived by teachers as an opportunity or as a difficulty. In the case of Portugal, it is important to mention that there is little research on stress and burnout in special education teachers. Nevertheless, these studies have reached similar conclusions as international studies (Jesus et al., 2014). For instance, Pinto et al. (2005) studied 777 regular teachers and their results showed that $54 \%$ of them considered the teaching profession as very stressful or extremely stressful, due to indiscipline of pupils and time pressures. Additionally, $6.3 \%$ revealed high burnout levels and 30\% were in a risk situation. Concerning the source of problems, several authors have pointed to difficulties in the collaboration work of both types of teachers, especially to limitations imposed by regular education teachers. McLeskey and Waldron (2000) point to coordination difficulties in the classroom related to a lack of a proper education for working with disabilities in regular teachers, as well as to a lack of time to work jointly and make necessary adjustments. Glat (2007) considers that the daily work is the main difficulty for regular teachers working with children with disabilities in regular classrooms, due to the presence of a diversity of pupils, each of them requiring special and different attention in their learning process. Some studies have found that teachers having more experience with children with disabilities display more positive attitudes to inclusion (Avramidis et al., 2000; Čagran \& Schmidt, 2011; Boer et al., 2010; Gyimah et al., 2009; Jerlinder et al., 2010; Rakap \& Kaczmarek, 2010). Portuguese studies coincide in these aspects; for example, Pinto and Morgado (2012) found that the attitudes of regular teachers to inclusion are influenced by the experience of working with children with disabilities. In this sense, it is also evident that a more positive attitude to inclusion is correlated with higher levels of exhaustion and burnout because teachers try to cope with all the diversity in the classroom. Sometimes, that became demanding and difficult, generating a feeling of frustration and tiredness (Talmor et al., 2005). Stress and burnout in regular and special education teachers is then a complex and multidimensional problem, resulting from 
an interaction of individual aspects and working environment, as we shall see below.

\section{STRESS AND BURNOUT IN INCLUSIVE SCHOOL WORKPLACE}

Teaching has been considered a major stressful profession. The International Labour Office has classified teaching as a profession of high physical and mental risk and proposes that stress could be defined as "the harmful physical and emotional response caused by an imbalance between the perceived demands and the perceived resources and abilities of individuals to cope with those demands" (International Labour Office [ILO], 2016, p. 2). Stress could be caused by work organization and design and happens when the demands of the profession do not match the competences of the employee. Thus, several workplace factors can induce a negative interaction between persons and the work environment and that may lead to emotional, cognitive, and behavioural problems and to risks for physical and mental health (Etzion, 2020). So the changes in workplace, as the introduction of inclusive rules for teaching and learning should be understood in terms of the impact for teachers, namely non-specialist teachers, because they only have a general training to cope with all children. For specialized teachers in special education this is also a new challenge because they need to work directly with non-specialist teachers in a mainstream school and in an inclusive class. It is undoubtedly a new and challengeable workplace. Previous studies show that teachers participating in inclusion processes seem to be prone to burnout states, health problems and exhaustion, incapacitating them to respond adequately to the pupils' needs. Fore et al. (2002) questioned 658 teachers about leaving the area of special education. They found a higher rate of persons leaving the profession compared to regular teachers. A majority left the area because they were overstressed by the pupils' needs and the responsibility, and they felt disdained and without power. Also, Stempien and Loeb (2002) studied 116 teachers of regular education and special education and found that special education teachers were the most unsatisfied and frustrated group. Only in Greece are the results quite different. Platsidou and Agaliotis (2008) found in 127 special education teachers low and medium levels of stress and slightly high levels of satisfaction. It seems to be due to factors related to the work conditions in the classroom and the good collaboration with other specialists and parents. Portuguese studies generally coincide with the former international results. For instance, Carlotto (2011) found among teachers high rates of burnout, characterized by physical and emotional exhaustion, anxiety, irritability, sleeplessness, even alcohol and drug abuse. The variables associated with higher levels of stress have been a field of research. In spite of the lack of agreement among different authors, some common factors have been identified (Seibt et al., 2013). These authors found significant differences related to gender, where women showed higher stress levels, and related to educational level, where teachers with lower education showed higher stress levels. Nevertheless, these data have not been confirmed by other authors. For instance, Esteras et al. (2014) studied a sample of 171 regular teachers, looking for predictive factors for stress and burnout, and found higher stress levels among male teachers. Küçüksüleymanoğlu (2011) carried out similar research with 67 special education teachers and found differences related to gender and educational level. Men reported higher levels of emotional exhaustion and depersonalization, whereas women reported lower rates of personal and professional achievement. No differences were found concerning educational level, but the authors point out that teachers with a higher education are prone to show higher levels of emotional exhaustion.

In this context it seems pertinent to carry out a study on the situation of Portuguese teachers, especially due to the fact that radical changes have occurred in the workplace in recent years, as a result of inclusion processes in the regular school. The aim the current study is thus to analyse stress and burnout levels in specialist (special education teachers) and non-specialist teachers (regular teachers) working in public schools, paying special attention to personal variables, such as age, professional experience and academic degree.

\section{PARTICIPANTS AND PROCEDURE}

\section{PARTICIPANTS}

The participants in this study were teachers (specialists and non-specialists), working in public education schools/groups of schools in Portugal. A convenient and nonprobability sampling method was used, based in online dissemination and an electronic platform to collect data because of their relative ease of access. The participants of this study were selected among a total population of 120,947 non-specialist teachers and 6109 specialist teachers working in public education in Portugal (DGEEC, 2014/2015). The sample is made up of 7528 teachers (Table 1), of whom 7086 (94.1\%) are non-specialists and 442 (5.9\%) are specialists working in special education. A comparison was made between the two groups in terms of gender, age and literacy, and it was observed that there were differences in relation to gender $[F(37.38,1), p<.001]$ and literacy $[F(461.34,4), p<.001]$, but not in relation to age $[F(53.00,47), p=.254]$, in which they are similar. This is an expected result, because the majority of teachers in Portugal are women, and special-
Stress and burnout in teaching 
Table 1

Participants

\begin{tabular}{|c|c|c|c|c|}
\hline Variables & Gender & Degree & Age (median) & $n(\%)$ \\
\hline \multirow{10}{*}{$\begin{array}{l}\text { Non-specialist } \\
\text { teachers }\end{array}$} & \multirow[t]{5}{*}{ Female } & Bachelor & 55 & $111(2.0)$ \\
\hline & & Graduation & 50 & $3615(66.1)$ \\
\hline & & Specialization & 49 & $559(10.2)$ \\
\hline & & Master degree & 48 & $1076(19.7)$ \\
\hline & & $\mathrm{PhD}$ & 50 & $106(1.9)$ \\
\hline & \multirow[t]{5}{*}{ Male } & Bachelor & 59 & $3(3.0)$ \\
\hline & & Graduation & 50 & $979(60.5)$ \\
\hline & & Specialization & 49 & $167(10.3)$ \\
\hline & & Master degree & 47 & $374(23.1)$ \\
\hline & & $\mathrm{PhD}$ & 50 & $66(4.1)$ \\
\hline \multirow[t]{10}{*}{ Specialist teachers } & \multirow[t]{5}{*}{ Female } & Bachelor & - & $0(0)$ \\
\hline & & Graduation & 52 & $87(22.0)$ \\
\hline & & Specialization & 47 & $158(39.9)$ \\
\hline & & Master degree & 48 & $142(35.9)$ \\
\hline & & PhD & 50 & $9(2.3)$ \\
\hline & \multirow[t]{5}{*}{ Male } & Bachelor & - & $0(0)$ \\
\hline & & Graduation & 55 & $13(28.3)$ \\
\hline & & Specialization & 41 & $14(30.4)$ \\
\hline & & Master degree & 46 & $17(37.0)$ \\
\hline & & PhD & 48 & $2(4.3)$ \\
\hline Total & - & - & - & $7528(100)$ \\
\hline
\end{tabular}

ized teachers have more training than non-specialist teachers.

\section{PROCEDURE}

This study follows the recommendations for improving the quality of web surveys, based on the Checklist for Reporting Results of Internet E-Surveys (CHERRIES) (Eysenbach, 2012). After selecting the questionnaires (Portuguese versions) in the paper version a test was made of the usability and functionality of the electronic questionnaires in the Limesurvey (version 2.05) platform with students of master's degree in education, special education and psychology $(n=20)$. This electronic questionnaire was preceded by an introduction with the identity of the research team and its institutional contact, the purpose of the study, the guarantees of anonymity, confidentiality and data use only for scientific purposes. Then the electronic questionnaire, within the whole project of research that supports this study, was submitted to the Scientific Council of Social Sciences School from the University of Evora and the Ministry of Education. After the approval, the questionnaire was sent to teachers in the Portuguese public schools. To create the database, each one of the questionnaires received by the Limesurvey platform and downloaded and transformed into an SPSS Statistics data file (version 22) was analysed. The next step was data analysis with software for data processing SPSS - Statistics Data and Document.

\section{INSTRUMENTS}

The Maslach Burnout Inventory (MBI), adapted to the Portuguese population by Martins (2008) and revised by Calisto (2017), was used to assess the levels of burnout manifested by the teachers.

Participants are asked to indicate a response based on the last three months of professional activity. It is 
a questionnaire composed of 22 items, using a Likert type scale, ranging from 1 (never) to 7 (always) and organized in three dimensions:

- Emotional exhaustion (8 items; $\alpha=.91$ ) - e.g. "I feel tired when I get up to go to work";

- Depersonalization (7 items; $\alpha=.79)$ - e.g. "I am worried that this work makes me colder emotionally";

- Personal and professional performance (7 items; $\alpha=.80)-$ e.g. "I feel that I can do useful things in my work".

These three dimensions account for $54.38 \%$ of the total variance. The internal consistency analysed using Cronbach's $\alpha$ was .91 for emotional exhaustion, .79 for depersonalization, .80 for personal and professional performance and .93 for the global score. High scores on the emotional exhaustion and depersonalization dimensions and low values for achievement are indicators of burnout.

The Stress Vulnerability Questionnaire adapted to the Portuguese population by Vaz-Serra (2000) and revised by Calisto (2017) was used to assess the stress levels presented by the teachers. The form of response is presented in a Likert type scale, ranging from 1 (I agree at all) to 5 (I disagree at all). So high levels of stress mean a low score in the scale in general and in each of its scales.

This questionnaire is composed of 23 items distributed in six dimensions:

- Perfectionism and frustration intolerance (6 items; $\alpha=.76)-$ e.g. "I feel bad when I am not perfect at what I do";

- Functional inhibition and dependence (5 items; $\alpha=.60)-$ e.g. "When you criticize me I tend to feel guilty";

- Lack of social support and deprivation of affect and rejection (5 items; $\alpha=.71$ ) - e.g. "When I have a problem to solve, I usually get someone who can help";

- Adverse living conditions (2 items; $\alpha=.77$ ) - e.g. "The money that I usually dispose of badly gives me essential expenses";

- Dramatization of existence (3 items; $\alpha=.59$ ) - e.g. "I am easily concerned with day-to-day setbacks";

- Subjugation (4 items; $\alpha=.60$ ) - e.g. "People only give me attention when they need me to do something to their advantage".

These dimensions explained $54.2 \%$ of global variance and presented a Cronbach's $\alpha$ of .88, for the global score.

Due to the lack of Portuguese standards, we used the scoring factor for the two instruments. In accordance with similar studies (Lazarus \& Folkman, 1984), a situational instruction was used. In the case of burnout, teachers were instructed to refer to the last three months of professional activity. For stress, the teachers were asked to honestly, quickly and spontaneously indicate the degree that best described their situation.

\section{DATA ANALYSIS}

The studies to compare stress and burnout in non-specialist and specialist teachers were performed based on descriptive statistics, using the software for data processing SPSS - Statistics Data Document. Thus, this research is organized in two parts. The first one analyses stress and burnout levels in specialist (special education teachers) and non-specialist teachers (regular teachers) working in inclusive schools, and its relations with personal variables (age, academic degree, professional experience). The second one analyses the association between stress and personal variables in burnout among teachers working in inclusive schools.

\section{RESULTS}

\section{DIFFERENCES IN STRESS AND BURNOUT IN SPECIALIST AND NON-SPECIALIST TEACHERS IN AN INCLUSIVE SCHOOL WORKPLACE}

A univariate analysis of variance was performed first, in order to identify which instrument dimensions showed differences between groups (Table 2). A further analysis was performed to find out for which of these groups this difference was significant. It was found that specialist teachers present higher levels of vulnerability to stress in the dimensions of lack of social support or deprivation $[F(1,7505)=6.21, p=.013]$ and perfectionism $[F(1,7505)=3.01, p=.083]$. Concerning burnout, significant differences were found between the two groups in two of the three dimensions and in the global index of burnout, with the regular teachers exhibiting higher scores of burnouts (dimensions and global index). Results were obtained in the dimensions of emotional exhaustion $[F(1,7507)=1.89, p=.170]$, depersonalization $[F(1,7507)=5.44, p=.012]$, and in personal and professional fulfilment $[F(1,7507)=6.21, p=.013]$ and in the global index of burnout $[F(1,7507)=6.35, p=.012]$.

Significant differences were found between the two groups in vulnerability to stress and in all the dimensions of burnout. The next step was to investigate the interaction between personal variables and vulnerability to stress and burnout.

\section{CORRELATIONS AMONG VARIABLES AND RATIONALE FOR REGRESSION MODELS}

We use Pearson's coefficient of correlation for variables with interval and numeric values and we use Spearman's coefficient of correlation for ordinal variables, as presented in Tables 3 and 4 .

The study of bivariate correlations shows that personal variables, namely age, academic degree
Stress and burnout in teaching 
Table 2

Comparison of levels of stress and burnout in non-specialist and specialist teachers

\begin{tabular}{lccccc}
\hline & Dimensions & \multicolumn{2}{c}{$M(S D)$} & $F$ & $p$ \\
\cline { 3 - 4 } & & Non-specialists & Specialists & & \\
\hline Stress & $\begin{array}{c}\text { Lack of social support and deprivation } \\
\text { of affection and rejection }\end{array}$ & $15.11(2.76)$ & $15.45(2.60)$ & 6.21 & .013 \\
& $\begin{array}{c}\text { Perfectionism and frustration intolerance } \\
\text { Inhibition and functional dependence }\end{array}$ & $10.79(2.29)$ & $10.98(2.22)$ & 3.01 & .083 \\
& Adverse living conditions & $19.30(3.20)$ & $19.44(3.12)$ & 0.43 & .514 \\
& $\quad 6.83(2.13)$ & $6.94(1.99)$ & 1.12 & .290 \\
& Subjugation & $17.79(4.11)$ & $17.75(4.15)$ & 0.03 & .872 \\
& Dramatization of existence & $8.89(2.30)$ & $8.81(2.34)$ & 0.51 & .477 \\
\hline Burnout & Emotional exhaustion & $36.28(11.65)$ & $35.50(11.18)$ & 1.19 & .170 \\
& $\quad$ Depersonalization & $14.15(7.22)$ & $13.30(6.43)$ & 6.21 & .013 \\
& Personal and professional fulfilment & $20.19(7.76)$ & $19.20(7.88)$ & 5.44 & .020 \\
& Burnout global & $70.63(20.73)$ & $68.10(19.40)$ & 6.35 & .012 \\
\hline
\end{tabular}

and professional experience, have a significant correlation with burnout and vulnerability to stress, as shown below. For the group of non-specialist teachers, the global score of burnouts correlated significantly $(p<.01)$ with all the dimensions of vulnerability to stress. When the burnout is higher (higher scores in MBI indicating more intense burnout), then the levels of vulnerability are more intense (more intense characteristics of vulnerability to stress mean low scores in the scale, which explains the negative correlation), namely: perfectionism ( $r=-.43)$, inhibition $(r=-.45)$, lack of social support $(r=-.43)$, adverse living conditions $(r=-.26)$, dramatization of existence $(r=-.40)$ and subjugation $(r=-.42)$. As far as the professional experience was concerned, there was also a significant and positive correlation with the global score of burnout $(r=.04)$, and a positive and significant correlation with stress vulnerability dimensions, which suggest lower stress vulnerability: adverse conditions $(r=.09)$ and subjugation $(r=.02)$. The same significant correlations were found for the variable age. The results for the variable academic degree present a significant correlation with perfectionism $(r=.04)$, inhibition $(r=.12)$, adverse living conditions $(r=.03)$, dramatization of existence $(r=.07)$ and subjugation $(r=.06)$.

The results showed, for the group of specialists, significant correlations $(p<.01)$ between the global score in burnout and all the dimensions of vulnerability to stress. When the burnout is higher, the levels of vulnerability are more intense (and the scores are lowest), and the correlations will be negative, namely: perfectionism $(r=-.44)$, inhibition
( $r=-.43)$, lack of social support $(r=-.46)$, adverse living conditions $(r=-.25)$, dramatization of existence $(r=-.40)$ and subjugation $(r=-.43)$. In the group of personal variables, the results point to positive and significant correlations between professional experience $(r=.13)$ and between academic degree and inhibition $(r=.11)$. The variable age correlates significantly with low vulnerability to stress [dramatization $(r=.16)$ and subjugation $(r=.11)]$. For this group of teachers, the results for the variable academic degree present a significant correlation only with inhibition $(r=.11)$.

The next step was to examine the predictive power of vulnerability to stress, professional experience, age and academic degree relative to burnout. A multiple linear regression analysis of variance was performed to understand the impact of the independent variables (vulnerability to stress and personal variables) in burnout (global index), for both groups. First, the residual independence using the DurbinWatson analysis was examined. The homoscedasticity was investigated by analysing the plots of residues versus non-standard predicted values for each group of teachers. The absence of multicollinearity was evaluated taking into account values higher than 0.2. The existence of outliers and tested high scores was analysed, eliminating studentized residuals greater than \pm 3 standard deviations, values greater than .2 and values above 1 for Cook's distance. Thus, a global model was tested, to evaluate the predictive power of these variables in both groups of teachers (non-specialists - Table 5, and specialists - Table 6). These models were intended to verify whether there were different explanatory patterns for non-special- 


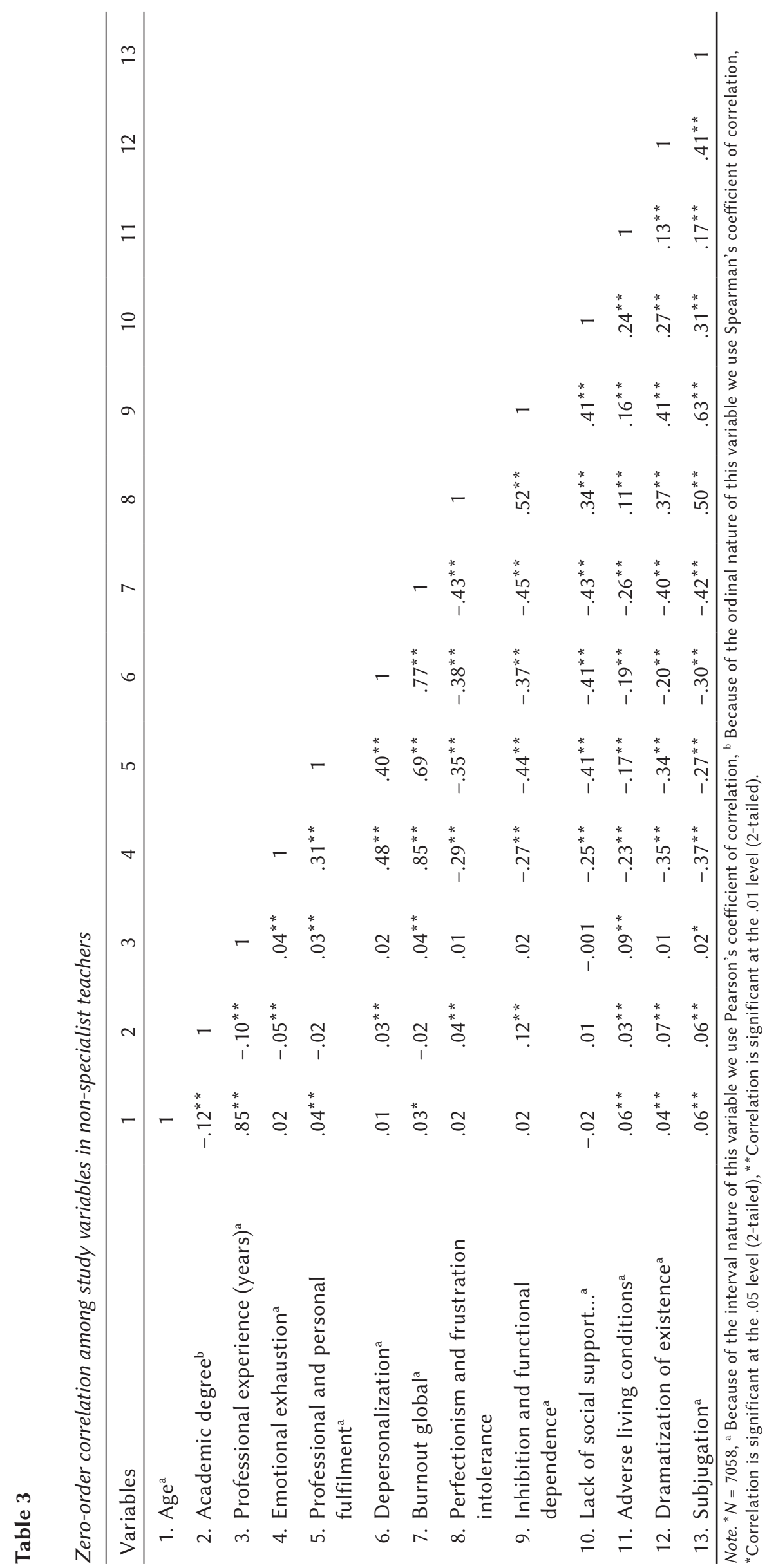

Stress and burnout

in teaching 


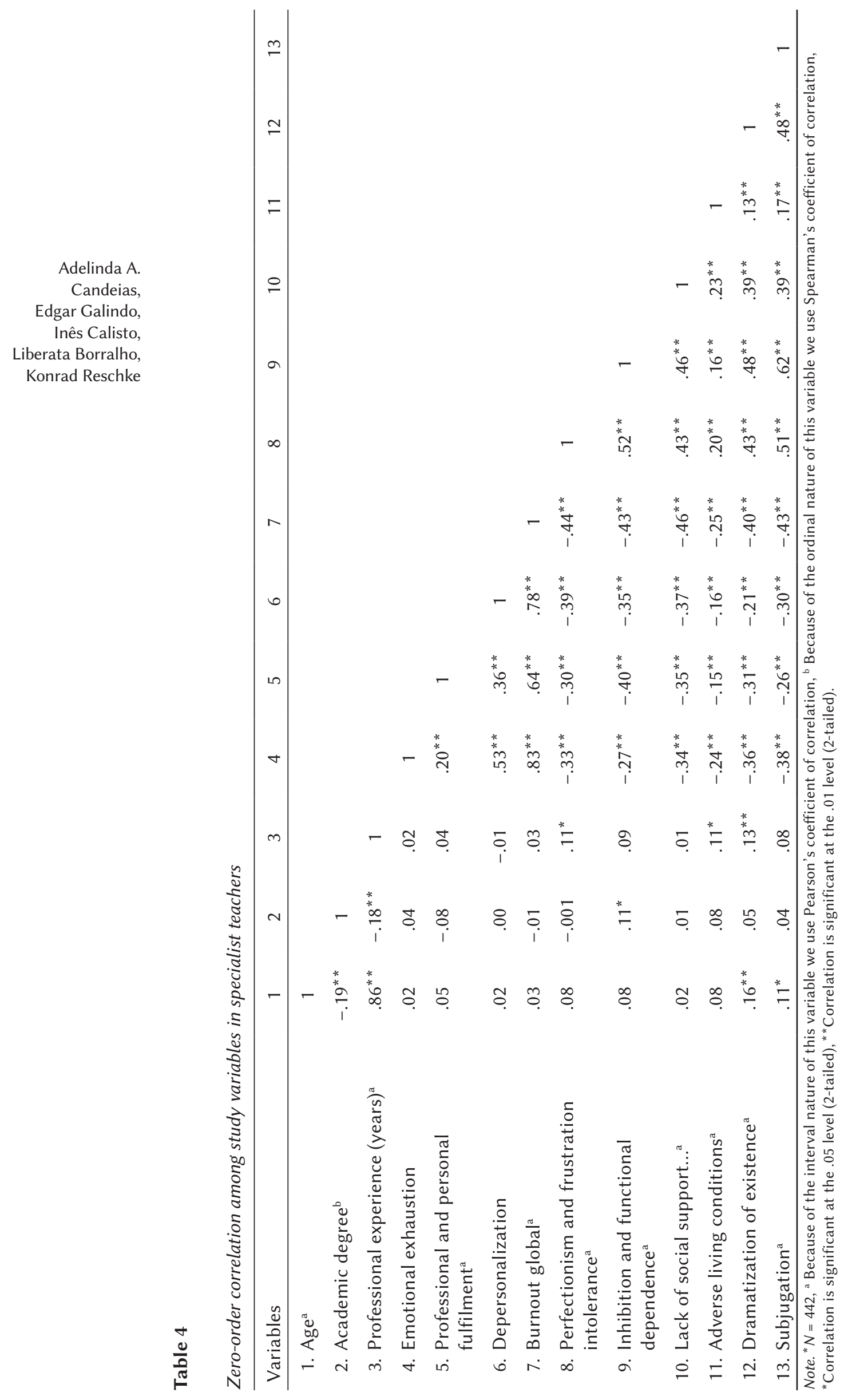


ist and specialist teachers in burnout. As can be seen (Table 5), in the general model for burnout in nonspecialist teachers (with a global predictive value of $36.5 \%$ ), inhibition and functional dependence is the most important predictive variable (19.9\%), followed by lack of social support (7.5\%), dramatization (4\%), perfectionism $(2.2 \%)$, adverse living conditions (1.9\%), subjugation $(0.5 \%)$, professional experience $(0.4 \%)$ and academic degree $(0.1 \%)$.

For specialists, as shown in Table 6, the predictive variables with the greatest impact (with a global predictive value of $34.3 \%$ ) were lack of social support, as the most important predictive variable (20.6\%), followed by perfectionism (7.4\%), subjugation (2.9\%), dramatization (1.2\%), adverse living conditions $(1.2 \%)$ and age $(0.1 \%)$.

\section{DISCUSSION}

The obtained results seem to show that, when comparing non-specialist and specialist teachers working with students with disabilities in inclusive schools, there is a difference in the level of vulnerability to stress. The group of specialists in special education reveals lower vulnerability related to social support or deprivation, a result coinciding with previous studies (Fore et al., 2002). On the other hand, the present study found the highest levels of burnout in non-specialist teachers in inclusive schools (in global score of burnout and in the dimensions of emotional exhaustion and personal and professional fulfilment), in contradiction with previous studies conducted in non-inclusive workplaces. For example, Lavian (2012) and Zabel and Zabel (2001) did not find differences between these two groups of teachers. Existence of the lowest levels of burnout among specialist teachers in the present study coincides with Boujut et al. (2016), who found that none of the teachers working with children with disabilities presented significant levels of burnout. The relationships between burnout, stress vulnerability, and age, professional experience and academic degree were also analysed. The results showed that higher levels of burnout are correlated with greater vulnerability to stress. Significant correlations $(p<.01)$ were found between the global index
Stress and burnout in teaching

\section{Table 5}

Summary of stepwise multiple regression analysis predicting burnout in non-specialist teachers $(n=7056)$

\begin{tabular}{|c|c|c|c|c|c|c|}
\hline Predictor variables & $\beta$ & $t$ & $p$ & Adjusted $R^{2}$ & $F$ & $p$ \\
\hline Inhibition and functional dependence & -.12 & -9.16 & $<.001$ & .20 & 506.76 & $<.001$ \\
\hline Lack of social support & -.22 & -20.12 & $<.001$ & .27 & & \\
\hline Dramatization & -.17 & -15.60 & $<.001$ & .31 & & \\
\hline Perfectionism & -.16 & -13.78 & $<.001$ & .34 & & \\
\hline Adverse living conditions & -.14 & -14.22 & $<.001$ & .36 & & \\
\hline Subjugation & -.10 & -7.75 & $<.001$ & .36 & & \\
\hline Professional experience (years) & .07 & 6.77 & $<.001$ & .36 & & \\
\hline Academic degree & .03 & 3.31 & .001 & .36 & & \\
\hline
\end{tabular}

Table 6

Summary of stepwise multiple regression analysis predicting burnout in specialist teachers $(n=450)$

\begin{tabular}{lcccccc}
\hline Predictor variables & $\beta$ & $t$ & $p$ & Adjusted $R^{2}$ & $F$ & $p$ \\
\hline Lack of social support & -.23 & -5.03 & $<.001$ & .21 & 40.10 & $<.001$ \\
Perfectionism & -.18 & -3.78 & $<.001$ & .28 & & \\
Subjugation & -.16 & -3.40 & .001 & .31 & & \\
Dramatization & -.16 & -3.45 & .001 & .32 & & \\
Adverse living conditions & -.13 & -3.20 & .002 & .33 & \\
Age & .11 & 2.74 & .006 & .34 & \\
\hline
\end{tabular}


Adelinda A.

Candeias,

Edgar Galindo,

Inês Calisto,

Liberata Borralho,

Konrad Reschke of burnout and higher vulnerability to stress (perfectionism, inhibition, lack of social support, feeling of living conditions as adverse, dramatization of existence and subjugation) in both groups of teachers. On the other hand, the professional experience correlates with a global score of burnout but the lowest stress vulnerability, namely in living situations as less adverse and being more resilient (less subjugation), for non-specialists, and less perfectionism and being more optimistic in living conditions and less dramatic, for specialist teachers. As observed, it seems that specific training and specialization protect the group of specialist teachers against burnout. The correlation between professional experience, age, and vulnerability with a minor level of stress seems to indicate that life and professional experience increase resilience to cope with stress. Finally, a relationship was observed between academic degree and disinhibition, in both groups. It seems that academic training (master's degrees, specializations courses and doctorate) incentivizes more resilience, lower inhibition and more independence, creating consequently lower vulnerability to stress. These results point to the existence of reciprocal influences among those variables, where academic and professional training and specialization in special education, and professional and academic level seem to be variables with multidimensional influence on decreased vulnerability to stress and consequently on health, wellbeing and quality of life, as well as on professional performance and efficacy in the workplace. These findings are in agreement with results of other researchers (Etzion, 2020; ILO, 2016; Küçüksüleymanoğlu, 2011; Pinto \& Morgado, 2012; Talmor et al., 2005).

Nevertheless, there are also differences in the levels of burnout expressed by the two groups of teachers. Non-specialist teachers expressed higher levels of burnout than specialist teachers, but when analysing the predictors of burnout for both groups, the main group of variables seems to be the dimensions of vulnerability to stress. Thus, vulnerability to stress plays an important role in this situation as a predictor of burnout, especially functional dependence, followed by lack of social support, dramatization, perfectionism, experiencing living conditions as adverse and subjugation, with a low contribution from variables associated with personal and professional development (age and professional experience). This means that when teachers in general feel vulnerability and dependence on others, low social support, and antagonism in the workplace, they are more exposed to development of burnout, fatigue and exhaustion, a finding in agreement with previous studies (see Etzion, 2020; ILO, 2016; Pinto \& Morgado, 2012). However, professional and specialized training could be an important factor of protection in the workplace, against stress and burnout, increasing professional fulfilment and assurance and resilience, as suggested previously (see Pinto \& Morgado, 2012; Talmor et al., 2005).

This study was conducted during a period of legislative and organizational changes in education in Portugal, with great implications for teachers. It is thus subject to methodological limitations related to the way the data were collected. Data were collected through voluntary participation in an online survey. On the other hand, the use of self-reported measures is conditioned by the effects of social desirability. Other methods such as teachers' reports about their own health should be used in future studies, based on focus groups and groups of support for teachers (Schraepen, 2011). In future studies, it will be important to extend the sample of teachers in special education to foster a comprehensive and systematic approach to stress and burnout levels in this group. It will also be important to deepen the study on the perception of social support in both quantitative and qualitative terms, since this seems to be part of the strategies used by teachers to cope with burnout.

\section{CONCLUSIONS}

The goal of the current study was to investigate stress and burnout conditions of teachers working presently in inclusive school workplaces and the corresponding influence of personal variables. The comparison between groups shows that the specialists in special education reveal lower vulnerability to social support, a fact in agreement with other studies (Fore et al., 2002), and that non-specialist teachers exhibit higher levels of burnout (in general and emotional exhaustion, and in personal and professional fulfilment), a result contradicting previous studies in non-inclusive workplaces (Lavian, 2012). As Boujut et al. (2016) found that teachers working with children with disabilities did not present higher levels of burnout, a fact that was associated with coping strategies developed through specific training. In general, the existence of correlations between burnout/stress vulnerability, on one hand, and professional experience/academic level, on the other hand, points to the crucial value of training and specialization in the topics of special and inclusive education, for both groups of teachers. Academic level seems to have an important impact on burnout, consequently on health, wellbeing and quality of life, as well as on professional performance and efficacy in the workplace, a fact also corroborated by Etzion (2020), ILO (2016) and Cunningham (2003). On a second level of analysis, the need for a training programme in stress management for teachers, based on an analysis of their needs, is evident. Intervention should enable teachers to develop strategies to deal more effectively with the new requests of the profession and to prevent burnout. In fact, if the source of stress depends 
largely on the exercise of teaching, then the solution must be a part of the school organization. The results obtained in the current study, on the one hand, corroborate other findings pointing to the importance of training and specialization for special education teachers. On the other hand, these results support the proposal of programmes centred on management of stress, relaxation/mindfulness and social/peer support (Flook et al., 2013; Schröder \& Reschke, 2010; Williams \& Poel, 2006) to improve teachers' skills to cope with stress/burnout and to improve their wellbeing, physical and mental health (Etzion, 2020; ILO, 2016). Now, stress in teachers is a variable that can also influence the performance of children at school (Boujut et al., 2016; Collie et al., 2012; Evers \& Tomic, 2003; Whitaker et al., 2015). Consequently, future research should not only concentrate on stress and burnout conditions of teachers, but also assess the influence of the levels of stress/burnout in teachers on the performance of children at school.

\section{RefERENCES}

Avramidis, E., Bayliss, P., \& Burden, R. (2000). A survey into mainstream teachers' attitudes towards the inclusion of children with special educational needs in the ordinary school in one local education authority. Educational Psychology, 20, 191-211. https://doi.org/10.1080/713663717

Boer, A., Pijl, S., \& Minnaert, A. (2010). Attitudes of parents towards inclusive education: a review of the literature. European Journal of Special Needs Education, 25, 165-181. https://doi.org/10.1080/ 08856251003658694

Boujut, E., Dean, A., Grouselle, A., \& Cappe, E. (2016). Comparative study of teachers in regular schools and teachers in specialized schools in France, working with students with an autism spectrum disorder: Stress, social support, coping strategies and burnout. Journal of Autism and Developmental Disorders, 46, 2874-2889. https://doi.org/10.1007/ s10803-016-2833-2

Čagran, B., \& Schmidt, M. (2011). Attitudes of Slovene teachers towards the inclusion of pupils with different types of special needs in primary school. Educational Studies, 37, 171-195. https://doi.org/ 10.1080/03055698.2010.506319

Calisto, I. (2017). Estudo comparativo de professores de ensino regular e educação especial em escolas públicas portuguesas: stresse, bem-estar, suporte social e burnout [Comparative study of regular and special education teachers in Portuguese public schools: Stress, well-being, social support and burnout]. Master's dissertation. University of Évora.

Candeias, A. A., Rosário, A. C., \& Saragoça, M. (2013). La mise en place de la CIF dans le système éducatif portugais: sa pertinence selon le point de vue de professionnels de l'éducation [The implementation of ICF in the Portuguese education system: Its relevance on the perspective of educational staff]. ALTER - European Journal of Disability Research, 7, 32-45. https://doi.org/10.1016/j.alter.2012.10.001

Carlotto, M. (2011). Burnout syndrome in teachers: Prevalence and associated factors. Psychology: Theory and Research, 27, 403-410. https://doi. org/10.1590/S0102-37722011000400003

Collie, R., Shapka, J., \& Perry, N. (2012). School climate and social-emotional learning: Predicting teacher stress, job satisfaction, and teaching efficacy. Journal of Educational Psychology, 104, 1189-1204. https://doi.org/10.1037/a0029356

Cunningham, T. (2003). The impact of inclusion on teacher burnout [Doctoral dissertation, Tennessee State University].

Decreto-Lei $n^{\circ}$ 3/2008, de 7 de Janeiro [Decree-Law No 3/2008 of 7th January]. Diário da República, I Série, No 4. Ministério da Educação.

Direção-Geral de Estatísticas da Educação e Ciência (DGEEC) (2014/2015). Perfil do docente 2014/2015 [Teacher profile 2014/2015]. Retrieved from https:// www.dgeec.mec.pt/np4/98/\%7B \$clientServletPa th\%7D/?newsld $=148 \&$ fileName $=$ DGEEC_DSEE_ DEEBS_PerfilDocente1415_An_li.pdf

Eysenbach, G. (2012). Correction: Improving the quality of web surveys: The Checklist for Reporting Results of Internet E-Surveys (CHERRIES). Journal of Medical Internet Research, 14, e8. https:// doi.org/10.2196/jmir.2042.

Esteras, J., Chorot, P., \& Sandín, B. (2014). Predicción del burnout en los docentes: Papel de los factores organizacionales, personales y sociodemográficos [Burnout prediction in teachers: Organizational, personal and socio-demographic factors]. Revista de Psicopatología y Psicología Clínica, 10, 79-92. https://doi.org/10.5944/rppc.vol.19.num.2.2014.13059

Evers, W., \& Tomic, W. (2003). Students' perceptions of the incidence of burnout among their teachers. Research in Education, 69, 1-15. https://doi.org/ 10.7227/RIE.69.1

Etzion, D. (2020). Work, vacation and well-being: Who's afraid to take a break? Routledge.

Flook, L., Goldberg, S., Pinger, L., Bonus, K., \& Davidson, R. (2013). Mindfulness for teachers: a pilot study to assess effects on stress, burnout and teaching efficacy. Mind Brain and Education, 7, 182-195. https://doi.org/10.1111/mbe. 12026

Fore, C., Martin, C., \& Bender, W. N. (2002). Teacher burnout in special education: The causes and the recommended solutions. The High School Journal, 86, 36-44. https://doi.org/10.1353/hsj.2002.0017

Gersten, R., Keating, T., Yovanoff, P., \& Harniss, M. (2001). Working in special education: Factor that enhances special educators' intent to stay. Exceptional Children, 67, 549-567. https://doi.org/10. 1177/001440290106700408
Stress and burnout in teaching 
Glat, R. (2007). Educação inclusiva: Cultura e cotidiano escolar [Inclusive education: Culture and school life]. Rio de Janeiro: 7 Letras.

Gyimah, E., Sugden, D., \& Pearson, S. (2009). Inclusion of children with special educational needs in mainstream schools in Ghana: Influence of teachers' and children's characteristics. International Journal of Inclusive Education, 13, 787-804. https:// doi.org/10.1080/13603110802110313

International Labour Office (ILO) (2016). Workplace stress. International Labour Office.

Adelinda A.

Candeias,

Edgar Galindo, Inês Calisto, Liberata Borralho, Konrad Reschke

Jerlinder, K., Danermark, B., \& Gill, P. (2010). Swedish primary-school teachers' attitudes to inclusion the case of PE and pupils with physical disabilities. European Journal of Special Needs Education, 25, 45-57. https://doi.org/10.1080/08856250903450830

Jesus, S., Miguel-Tobal, J., Rus, C., Viseu, J., \& Gamboa, V. (2014). Evaluating the effectiveness of a stress management training on teachers and physicians' stress related outcomes. Clínica y Salud, 25, 111-115. https://doi.org/10.1016/j.clysa.2014.06.004

Küçüksüleymanoğlu, R. (2011). Burnout syndrome levels of teachers in special education in Turkey. International Journal of Special Education, 26, 53-63.

Lavian, R. (2012). The impact of organizational climate on burnout among homeroom teachers and special education teachers (full classes/individual pupils) in mainstream schools. Teachers and Teaching: Theory and Practice, 18, 233-247. https:// doi.org/10.1080/13540602.2012.632272

Lazarus, R. S., \& Folkman, S. (1984). Stress, appraisal, and coping. Springer.

McLeskey, J., \& Waldron, N. (2000). Inclusive schools in action: Making differences ordinary. ASCD.

Martins, J. (2008). Burnout na profissão docente (Dissertação de Mestrado) [Burnout in the teaching profession (Master's dissertation)]. Faculdade de Psicologia e Educação.

Pinto, A., Lima, M., \& Silva, A. (2005). Fuentes de estrés, burnout y estratégias de coping en professores portugueses [Stress sources, burnout and coping among Portuguese teachers]. Revista de Psicología del Trabajo y de las Organizaciones, 21, 125-143.

Pinto, N., \& Morgado, J. (2012). Atitudes de pais e professores perante a inclusão [Atitutudes of parents and teachers to inclusion]. In L. Mata, F. Peixoto, J. Morgado, J. C. Silva, \& V. Monteiro (Eds.), Actas do $12 .^{\circ}$ Colóquio Internacional de Psicologia e Educação: Educação, aprendizagem e desenvolvimento: Olhares contemporâneos através da investigação e da prática [Proceedings of the 12th International Colloquium on Psychology and Education: Education, learning and development: Contemporary views through research and practice] (pp. 471-491). ISPA - Instituto Universitário.

Pinto, A., \& Alvarez, M. (2016). Promoção da saúde ocupacional em contexto escolar: da saúde física ao bem-estar profissional em professores [Promotion of occupational health in school context: From physical health to professional well-being in teachers]. In M. Chambel (Ed.), Psicologia da saúde ocupacional (Occupational health psychology) (pp. 135-166). Pactor.

Platsidou, M., \& Agaliotis, I. (2008). Burnout, job satisfaction and instructional assignment-related sources of stress in Greek special education teachers. International Journal of Disability, Development and Education, 55, 61-76. https://doi. org/10.1080/10349120701654613

Rakap, S., \& Kaczmarek, L. (2010). Teachers' attitudes towards inclusion in Turkey. European Journal of Special Needs Education, 25, 59-75. https://doi. org/10.1080/08856250903450848

Schraepen, B. (2011). Constructing inclusive coaching. In J. Lebeer, A. Candeiasand, \& L. Grácio (Eds.), With a different glance. Dynamic assessment and functioning of children oriented at development \& inclusive learning (pp. 153-164). Garant.

Schröder, H., \& Reschke, K. (2010). Optimistisch den Stress Meistern [Optimistic management of stress]. DGVT-Verlag.

Seibt, R., Spitzer, S., Druschke, D., Scheuch, K., \& Hinz, A. (2013). Predictors of mental health in female teachers. International Journal of Occupational Medicine and Environmental Health, 26, 856-869. https://doi.org/10.2478/s13382-013-0161-8

Simeonsson, R. J., Sauer-Lee, A., Granlund, M., \& Björck-Åkesson, E. (2010). Developmental and health assessment in rehabilitation with the ICF for children and youth. In E. Mpofu \& T. Oakland (Eds.), Rehabilitation and health assessment. Applying ICF guidelines (pp. 27-46). Springer Publishing Company.

Stempien, L. R., \& Loeb, R. C. (2002). Differences in job satisfaction between general education and special education teachers' implications for retention. $R e$ medial and Special Education, 23, 258-267. https:// doi.org/10.1177/07419325020230050101

Talmor, R., Reiter, S., \& Feigin, N. (2005). Factors relating to regular education teacher burnout in inclusive education. European Journal of Special Needs Education, 20, 215-229. https://doi.org/10.1080/ 08856250500298012

The United Nations (2006). Convention on the Rights of Persons with Disabilities. Retrieved from https:// www.un.org/development/desa/disabilities/convention-on-the-rights-of-persons-with-disabilities.html

Vaz-Serra, A. (2000). Construção de uma escala para avaliar a vulnerabilidade ao stress [Construction of a scale to assess vulnerability to stress]. Psiquiatria Clínica, 21, 279-308.

Williams, K., \& Poel, E. (2006). Stress management for special educators: The self-administered tool for awareness and relaxation (STAR). Teaching Exceptional Children Plus, 3, 1-12. 
Whitaker, R., Dearth-Wesley, T., \& Gooze, R. (2015). Workplace stress and the quality of teacher-children relationships in Head Start. Early Childhood Research Quarterly, 30, 57-69. https://doi.org/ 10.1016/j.ecresq.2014.08.008

World Health Organization (2001). International Classification of Functioning, Disability and Health - ICF. Retrieved from http://www.handicapincifre. it/documenti/ICF_18.pdf

Zabel, R., \& Zabel, M. (2001) Revisiting burnout among special education teachers: do age, experience, and preparation still matter? Teacher Education and Special Education, 24, 128-139. https://doi. Stress and burnout org/10.1177/088840640102400207 